\title{
Analysis and calculation of induced lightning over-voltage in wind farm Jian $\mathrm{WU}^{1,}$, Lidong $\mathrm{WU}^{2, \mathrm{~b}}$ \\ ${ }^{1}$ School of Resources and Materials of Northeastern University at Qinhuangdao, Qin Huangdao, 066000, China \\ ${ }^{2}$ China Dating Corporation Renewable Power Co.Limited, Beijing, 100800, China \\ aemail: 820730266@qq.com, bemail: 13718011660@163.com
}

Keywords: Collector Circuit; Induced Lightning Over-voltage; Effect Factors

\begin{abstract}
With the construction of large-scale wind farm, most of wind farms' geographical environment is more open, vulnerable to line switch tripping caused by large-scale wind power failure. Therefore line lightning protection becomes important work of wind farm construction. In this paper, lines lightning protection is preceded through analyzing and calculating lightning induced voltage in the mathematical model to determine the optimal calculation model, without considering the influence of environmental factors such as temperature, humidity and terrain. The relationship between each influencing factor and induced lightning over-voltage is analyzed by using MATLAB.
\end{abstract}

\section{Introduction}

Lightning phenomenon is the opposite charge of thundercloud or long distance belt phenomenon of atmospheric discharge charge between thundercloud and the earth. It can directly or indirectly cause damage to ground facilities. In the harsh natural conditions under strong lightning activity factors and terrain effects, lightning is caused by high accident rate. At the same time, lightning is an important endanger factor for operation of farm equipment when it invades wind farms along propagation path

According to the strike point of different classification, lightning of the overhead line is divided into lightning over-voltage and lightning induced over-voltage. Lightning over-voltage is firstly recognized through direct observation to judge. The lightning induced over-voltage is not intuitive and less cognitive, but it exists in the operation of electric circuit, and that is an important influence factor, especially in the higher elevations or plateau area[1].

Lightning induced voltage calculation method is commonly numerical calculation method including lightning return stroke model, electromagnetic field propagation model, electromagnetic field and transmission line coupled model to analyze lightning strike calculation near the line of induction voltage level[2-3]. Literature [4] has shown that early development of pilot discharge is possible to cause action of relay protection device .Literature [5] only considers impact on spatial location, not establishes lightning over-voltage as a function of time .Literature [6]is proposed to consider pilot lightning discharge process and fight back over-voltage calculation method, but it can't study factors lightning over-voltage.

Considering lightning leader discharge and glow discharge process, this paper presents calculation method of lightning over-voltage, based on reasonable mathematical model of electromagnetic field and transmission line coupled to calculate lightning line over-voltage, line coupling model by MATLAB simulation analyzes influencing factors to lightning over-voltage, obtained various factors and lightning over-voltage relationship. 


\section{Calculation of lightning over-voltage}

\section{Lightning current development process}

Negative polarity lightning downward is most common discharge types in thunder cloud to earth , so this article focuses on negative polarity lighting down. Thunder clouds in the discharge process of the earth are divided into three stages: leader discharge phase, main discharge phase and glow discharge phase. Because current amplitude of glow discharge lightning is not large, impact is neglected on the power system. Therefore, we focus on leader discharge phase and main discharge phase, that is the first stage in lightning process.

\section{Current model at the bottom of lightning channel}

The bottom of the channel current model is expressed as product of two functions, it is described as :

$$
i(0, t)=I_{0} x(t) y(t)
$$

Where: $I_{0}$ is peak current at the bottom of channel; $\tau_{1}$ is leading time constant; $\tau_{2}$ is delay time constant; $\eta$ is peak correction coefficient; $n$ is exponent.

\section{Calculation of electromagnetic field around lightning channel}

Current is decomposed into infinite number of current cells in lightning channel, which current element $i(z, t) d t$ at any height $\mathrm{z}$ is viewed as a dipole with change rate of time. Electromagnetic field of each current element is calculated, and then the electromagnetic field around the lightning channel can be obtained by integrating the whole return path integral [7]. In general, considering the earth as a pure conductor, and electromagnetic field is calculated according to the principle of mirror image method.

Based on cylindrical coordinate system in Fig.1, differential expression of electromagnetic field component is induced by lightning current at any position $(r, \varphi, z)$ around lightning current

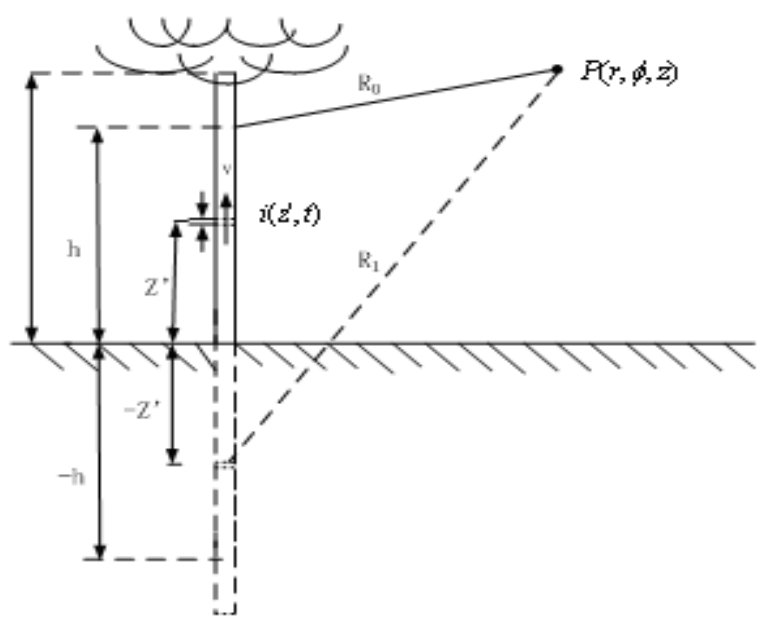

Fig.1 lightning current electromagnetic field of the earth reflection channel as:

$$
\begin{aligned}
& d H_{\varphi}(r, \varphi, z, t)=\frac{d z^{\prime}}{4 \pi}\left[\frac{r}{R^{3}} i\left(z^{\prime}, \frac{t-r}{c}\right)+\frac{r}{c R^{2}} \frac{\partial i\left(z^{\prime}, \frac{t-r}{c}\right)}{\partial t}\right] \\
& d E_{\varphi}(r, \varphi, z, t)=\frac{d z^{\prime}}{4 \pi \varepsilon_{0}}\left[\begin{array}{l}
\frac{3 r\left(z-z^{\prime}\right)}{R^{5}} \int_{0}^{t} i\left(z^{\prime}, \tau-R / c\right) d t+\frac{3 r\left(z-z^{\prime}\right)}{c R^{4}} i\left(z^{\prime}, t-R / c\right) \\
+\frac{r\left(z-z^{\prime}\right)}{c^{2} R^{3}} \frac{\partial i\left(z^{\prime}, t-R / c\right)}{\partial t}
\end{array}\right] \\
& d E_{z}(r, \varphi, z, t)=\frac{d z^{\prime}}{4 \pi \varepsilon_{0}}\left[\begin{array}{l}
\frac{2 r\left(z-z^{\prime}\right)^{2}-r^{2}}{R^{5}} \int_{0}^{t} i\left(z^{\prime}, \tau-R / c\right) d t \\
+\frac{2\left(z-z^{\prime}\right)^{2}-r^{2}}{c R^{4}} i\left(z^{\prime}, t-R / c\right)-\frac{r^{2}}{c^{2} R^{3}} \frac{\partial i\left(z^{\prime}, t-R / c\right)}{\partial t}
\end{array}\right]
\end{aligned}
$$

Where: $r, \varphi$ and $z$ respectively under cylindrical coordinate radial coordinates, azimuth angle and 
axial coordinates; $R$ is a current dipole to point distance, $R_{0}$ is the physical channel current scene point distance, $R_{1}$ is current mirror to the distance; $\mu_{0}, \varepsilon_{0}$ and $c$ respectively for vacuum permittivity, permeability and light speed; $z$ 'represents coordinates of lightning current element; $h$ represents height of channel current.

Ground reflection effect is obtained according to mirror image principle, which is superposed of the electromagnetic field generated by mirror current and actual channel current, that is to obtain the electromagnetic field of any point in the space. Hence integral expression is obtained by electromagnetic field generated by lightning current at space point $(r, \varphi, z)$ :

$$
\begin{aligned}
& H_{\varphi}(r, \varphi, z, t)=\frac{d z^{\prime}}{4 \pi}\left\{\begin{array}{l}
\int_{0}^{H}\left[\frac{r}{R_{0}{ }^{3}} i\left(z^{\prime}, t-R_{0} / c\right)+\frac{r}{c R_{0}{ }^{2}} \frac{\partial i\left(z^{\prime}, t-R_{0} / c\right)}{\partial t}\right] d z^{\prime} \\
+\int_{0}^{H}\left[\frac{r}{R_{1}{ }^{3}} i\left(z^{\prime}, t-R_{1} / c\right)+\frac{r}{c R_{1}{ }^{2}} \frac{\partial i\left(z^{\prime}, t-R_{1} / c\right)}{\partial t}\right] d z^{\prime}
\end{array}\right\} \\
& E_{r}(r, \varphi, z, t)=\frac{1}{4 \pi \varepsilon_{0}}\left\{\begin{array}{l}
\int_{0}^{H}\left[\begin{array}{l}
\frac{3 r\left(z-z^{\prime}\right)}{R_{0}^{5}} \int_{0}^{t} i\left(z^{\prime}, t-R_{0} / c\right) d t \\
+\frac{3 r\left(z-z^{\prime}\right)}{c R_{0}^{4}} i\left(z^{\prime}, t-R_{0} / c\right)+\frac{r\left(z-z^{\prime}\right)}{c^{2} R_{0}^{3}} \frac{\partial i\left(z^{\prime}, t-R_{0} / c\right)}{\partial t}
\end{array}\right] d z^{\prime} \\
+\int_{0}^{H}\left[\begin{array}{l}
\frac{3 r\left(r+r^{\prime}\right)}{R_{1}^{5}} \int_{0}^{t} i\left(z^{\prime}, t-R_{1} / c\right) d t \\
+\frac{3 r\left(r+r^{\prime}\right)}{c R_{1}^{4}} i\left(z^{\prime}, t-R_{1} / c\right)+\frac{r\left(z+z^{\prime}\right)}{c^{2} R_{1}^{3}} \frac{\partial i\left(z^{\prime}, t-R_{1} / c\right)}{\partial t}
\end{array}\right] d z^{\prime}
\end{array}\right\} \\
& E_{s}(r, \varphi, z, t)=\frac{1}{4 \pi \varepsilon_{0}}\left\{\begin{array}{l}
\int_{0}^{H}\left[\begin{array}{l}
\frac{2\left(z-z^{\prime}\right)^{2}-r^{2}}{R_{0}{ }^{5}} \int_{0}^{t} i\left(z^{\prime}, t-R_{0} / c\right) d t \\
+\frac{2\left(z-z^{\prime}\right)^{2}-r^{2}}{c R_{0}{ }^{4}} i\left(z^{\prime}, t-R_{0} / c\right)+\frac{r^{2}}{c^{2} R_{0}^{3}} \frac{\partial i\left(z^{\prime}, t-R_{0} / c\right)}{\partial t}
\end{array}\right] d z^{\prime} \\
+\int_{0}^{H}\left[\begin{array}{l}
\frac{2\left(z-z^{\prime}\right)}{R_{1}{ }^{t}} \int_{0}^{t} i\left(z^{\prime}, t-R_{1} / c\right) d t \\
+\frac{2\left(z-z^{\prime}\right)-r^{2}}{c R_{1}^{4}} i\left(z^{\prime}, t-R_{1} / c\right)-\frac{r^{2}}{c^{2} R_{1}^{3}} \frac{\partial i\left(z^{\prime}, t-R_{1} / c\right)}{\partial t}
\end{array}\right] d z^{\prime}
\end{array}\right\}
\end{aligned}
$$

\section{Calculation of lightning induced over-voltage of overhead transmission line}

Lightning induced voltage of the overhead transmission line is the actual calculation of field excitation line voltage and current response, namely the field line coupling problem. A general method solves the Maxwell equations based on the antenna theory .

The following will use the Taylor model, considering the effect of the uniform plane wave, the transmission line equation and its solution.

Two wire transmission line structure shown in Fig.2, according to Maxwell equation $\nabla \times \vec{H}=j w \varepsilon \vec{E}+\vec{J}$, Stokes Theorem is used $\oiint_{s} \nabla_{s} \times \vec{F} \cdot d \vec{S}=0$ and formula (8) is as follows:

$$
I(x+\Delta x)-I(x)+j w \varepsilon \iint_{S 1} E_{r} r d \phi d x=0
$$

On both sides divided by $\Delta x$, formula is obtained when $\Delta x \rightarrow 0$ and $r \rightarrow a$,:

$$
\frac{d I(x)}{d x}+j w \varepsilon \int_{0}^{2 \pi} E_{r}^{s c a}(x) a d \phi+j w \varepsilon \int_{0}^{2 \pi} E_{r}^{i n c}(x) a d \phi=0
$$




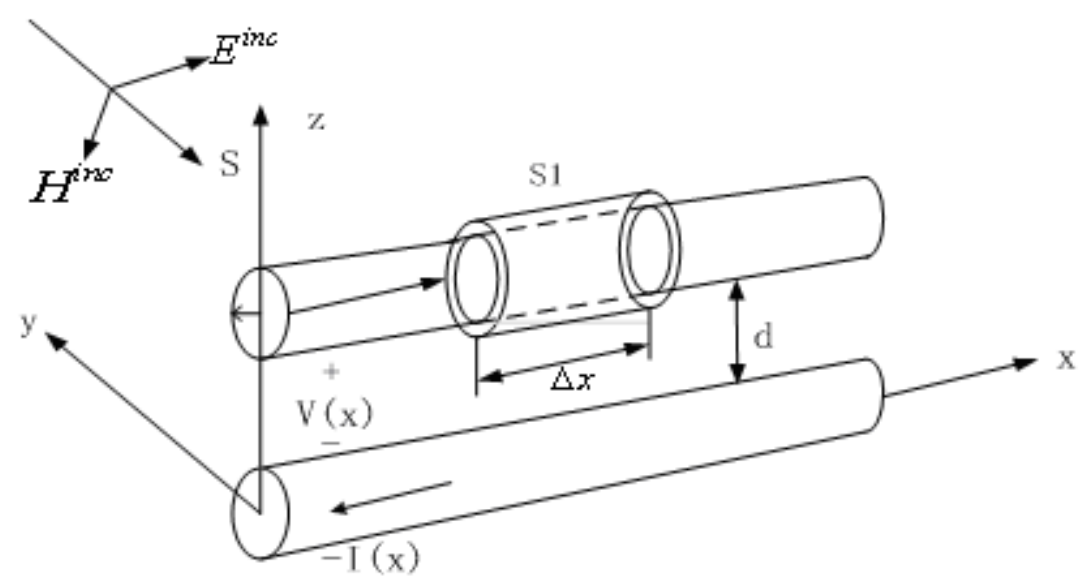

Fig.2 Transmission structure diagram without frequency-dependent parameters Due to $a<<d$, the electric field near wire is independent of incident azimuth $\phi$ :

$$
j w \varepsilon \int_{0}^{2 \pi} E_{r}^{s c a}(x) a d \phi=j w \varepsilon 2 \pi a E_{r}^{s c a}(x)=j w q^{\prime}(x)
$$

Because there is no free charge in free space of wire, so:

$$
\int_{0}^{2 \pi} E_{r}^{i n c}(x) a d \phi=0
$$

Formula (10) and (11) are carried into formula (9):

$$
\frac{d I(x)}{d x}+j w q^{\prime}(x)=0
$$

The unit length of transmission line capacitance is $C^{\prime}$, according to the relationship between the voltage and the charge, there are:

$$
q^{\prime}(x)=C^{\prime} V^{\prime s c a}(x)
$$

The total voltage between the wires is:

$$
V(x)=V^{i n c}(x)+V^{s c a}(x)=-\int_{0}^{d} E_{z}^{i n c}(x, z) d+V_{z}^{s c a}(x)
$$

So the equation can be written:

$$
\frac{d I(x)}{d x}+C^{\prime} V(x)=I_{S 1}^{\prime}(x)
$$

Where: $I_{S 1}^{\prime}(x)=-j w C^{\prime} \int_{0}^{d} E_{z}^{i n c}(x, z) d z$

\section{Simulation Comparison}

According to relevant parameters of reference [6], transmission line equation is solved by FDTD method and simulated through MATLAB software. In contrasted with lighting induced over-voltage shown in Fig.3 and Fig.4, amplitude and change tendency of lightning speed induction is roughly same. Lightning speed increases, lightning induced voltage gradient also increases, and amplitude decreases. This trend is consistent with induced lightning over-voltage in Fig.4. So it is correct to calculate lightning over-voltage of overhead line in this paper. 


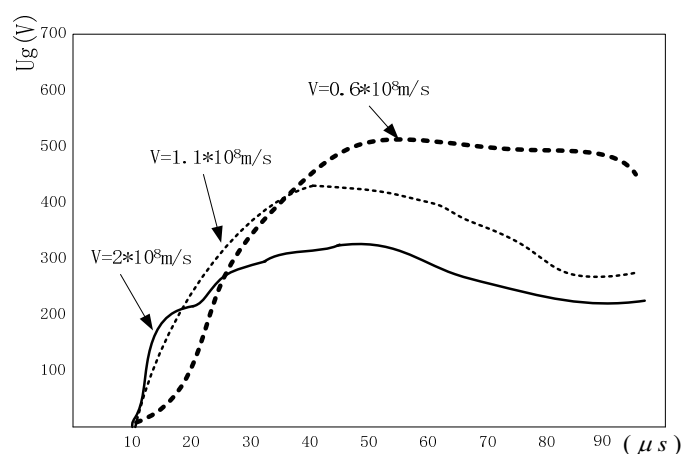

Fig. 3 simulation trend curves of induced over-voltage in this paper

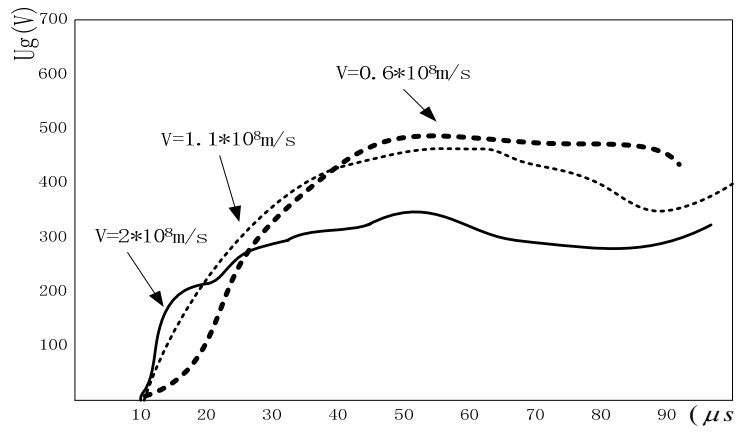

Fig.4 trend curves of induced over-voltage in reference [6]

\section{Factors affecting induced lightning over-voltage}

Actual line situation is complicated and changeable, thus lots of factors will affect induction lightning over-voltage, such as lightning current amplitude, return stroke speed, lightning distance etc.Lightning current amplitude, return stroke speed, striking distance of induced lightning over-voltage amplitude is analyzed. Based on model of induced lightning over-voltage, induced lightning over-voltage is calculated.

\section{Lightning current amplitude}

Electrostatic and electromagnetic components of lightning over-voltage are unified by mutation of electromagnetic field and simultaneously produced. From electrostatic component, lightning current amplitude is more bigger, field strength is more stronger, wire bound charge induction is more also. And bound charge in the main discharge stage is more smaller, also causing electrostatic component to increase; From electromagnetic component, the larger magnitude of lightning current, leading to wire - earth loop portions of flux increased over time rate of change, which leads to increase of electromagnetic component. Therefore, induced lightning over-voltage increases with amplitude of e lightning current.

Other variables remain unchanged, $\mathrm{I}$ is taken 15KA, 50KA, 100KA respectively. Effect on different lightning current amplitudes caused by induced lightning over-voltage shown in Fig.5. Lightning current amplitude is larger, lightning induced voltage amplitude is larger, and with lightning current amplitude increases proportionately, steepness of wave head also increases significantly.

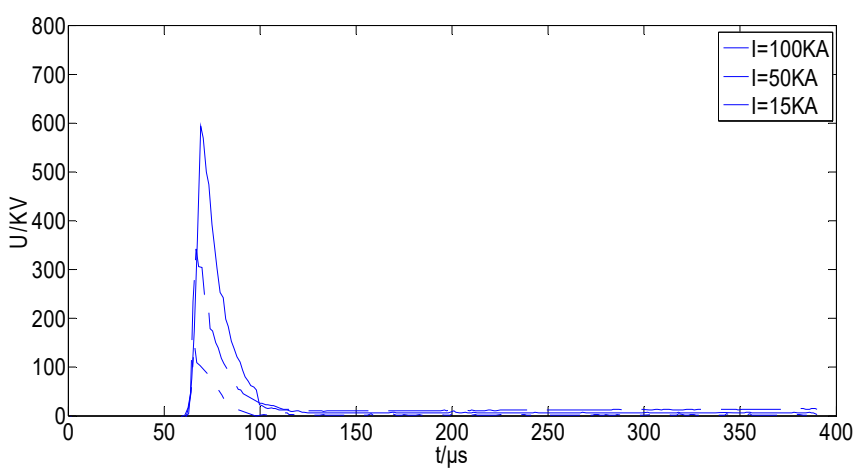

Fig.5 Amplitude of lightning current effect on lightning over-voltage

\section{Return stroke speed}

Other variables remain unchanged, and $v_{f}$ is taken $70 \mathrm{~m} \mu \mathrm{s}, 130 \mathrm{~m} \mu \mathrm{s}, 200 \mathrm{~m} \mu \mathrm{s}$. Results of return stroke speed of lightning over-voltage are shown in Fig.6.

When lightning current return stroke speed increases, radiation electrostatic field component of over-voltage in the return stroke process decreases, leading to amplitude decrease of lightning current. 


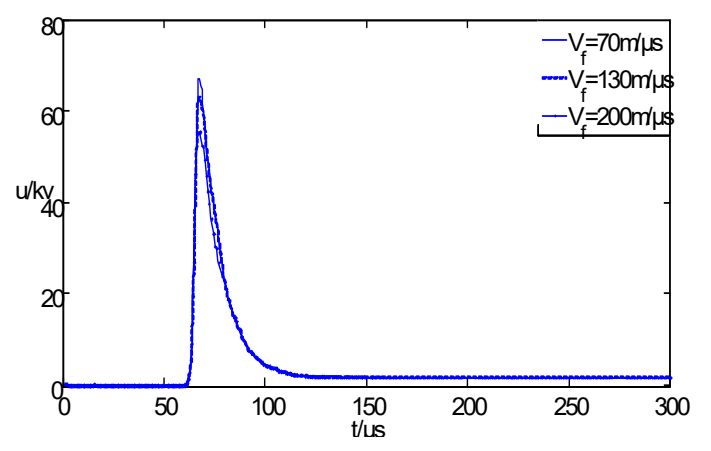

Fig.6 Return stroke effect on lightning over-voltage

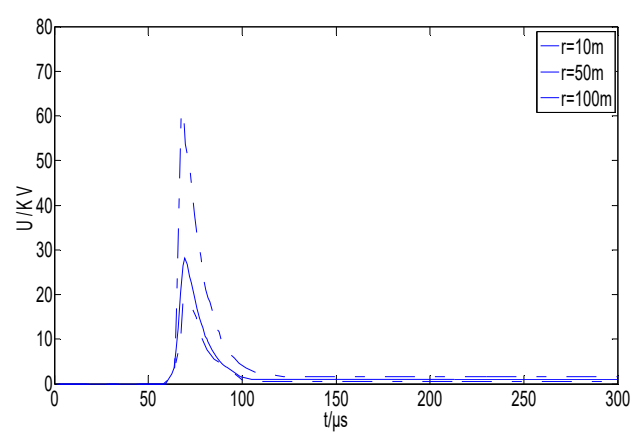

Fig.7 Lighting distance effect on lightning over-voltage

\section{Lightning strike distance}

Other variables remain unchanged, $\mathrm{r}$ is taken $100 \mathrm{~m}, 50 \mathrm{~m}, 10 \mathrm{~m}$. Lightning strike distance impact on lightning over-voltage is shown in Fig.7.

In summary, lightning current amplitude, return stroke speed, lightning strike distance and so on, all have influences on magnitude of induced lightning over-voltage. It suggests that lightning protection design should select proper lightning current amplitude reference value, not less than average value. Under considering line height and buildings, return stroke speed is calculated according to characteristics of different regions, and takes measurement of safe and economic anti thunder.

\section{Conclusions}

In this paper, lines lightning protection is studied on wind farm collector and analyzed mathematical model for calculation of lightning voltage. Without considering temperature, humidity, terrain and other environmental factors, best model program is determined. Relationships between lightning over-voltage and effect factors are obtained, and lightning transformation method is proposed .Less long needle on the tower head can limit lightning over-voltage, lightning arrester is used to limit lightning over-voltage. Operational experience shows that this method has high scientific and practical.

\section{References}

[1] Li Jinglu .High Voltage Engineering[M].Bei jing:China Water Power Press,2007,144-280

[2] Liu Gang, Xu Bin, Wang Xiao-min. Calculation Method on Lightning Trip-out Rate of Transmission Lines Considering the Influence of Power Frequency Voltage[J].High Voltage Engineering, 2013,39(6):1481-1497.

[3] Claus Leth Bak, Kristin Erla Einarsdóttir, Einar Andresson. Overvoltage Protection of Large Power Transformers-A Real Life Study Casere[J]. IEEE Transacion on Power Delivery, 2008, 23(2): 657-666

[4] Zhu Hai-ming. A Dissertation Submitted for the degree of master[D].Guang zhou:South China University Of Technology,2012

[5]Yu Zhan-qing, Zeng Rong.Simulation Calculation and Analysis of Lightning Induced Over-voltage on Power Distribution Lines[J].High Voltage Engineering, 2013,39(2): 415-422

[6] Xu Xing-fa, Nie Yi-xiong, Cheng Han-xiang. A calculation method of lightning induced over-voltage with improved Agra WA the model and FDTD method[J].Southern Power System Technology,2014,29(6):70-77

[7] Chen Si-ming,Yin Hui. Analysis on Transient Characteristic of Induction Thunder Over-voltage in $10 \mathrm{kV}$ Overhead Distribution Lines[J].Insulators and Surge Arresters, 2014 (2): 90-96 